\title{
Pesquisa de satisfação dos clientes de uma loja de materiais de construção de Itararé-SP
}

\section{Customer satisfaction research of a building supply store of Itararé-SP}

\author{
FAFIT Faculdades Integradas de Itararé \\ e-mail: mah.rosas@hotmail.com
}

Claudia Tania Picinin

Universidade Positivo/FAFIT Faculdades Integradas de Itararé

Recebido em 25 de novembro de 2011. Aprovado em 05 de outubro de 2012

Editor Responsável: Edson Roberto Scharf, Dr.

Processo de avaliação por double blind review

Resumo: O objetivo geral do presente trabalho delimita-se em mensurar o nível de satisfação dos clientes de uma loja de materiais de construção no interior de São Paulo entre a importância atribuída pelos clientes com relação ao desempenho atribuído pelos clientes. O referencial teórico aborda a satisfação dos clientes, bem como a análise da matriz de importância $\mathrm{X}$ desempenho. A presente pesquisa teve uma abordagem quantitativa com aplicação de um questionário, cujo recorte de estudo foi uma única loja do setor de materiais de construção do município de Itararé-SP. Os dados foram coletados através de um questionário composto por oito questões. Com os dados obtidos, evidencia-se que a maioria dos consumidores são residentes em Itararé-SP, do sexo masculino, com faixa etária entre 19 e 36 anos e são casados. Os clientes frequentam a loja várias vezes, sendo que classificam as variáveis entrega domiciliar e estacionamento como pontos fortes do estabelecimento.

Palavras-chave: Marketing, satisfação dos clientes, lealdade.

Abstract: The objective of this paper is to measure the customer satisfaction level of a building supply store located on an interior city of the federal state of São Paulo between importance attributed by the customers regarding the performance attributed, underpinnings boards customer satisfaction as well as analysis importance and performance matrix. The present research had a quantitative approach with application of a survey, concerning a single store in sector of construction materials on the municipality of Itararé-SP. From the obtained data, it was evidenced that most of consumers live in Itararé-SP, are men, with age between 19 and 36 years old and are married. The customers frequent the store several times a month, and classify the home delivery and parking as strong points of the establishment.

Keywords: Marketing, customer satisfaction, loyalty.

\section{Introdução}

O marketing pode ser entendido como um sistema de planejamento e execução, que engloba atividades para estabelecer preços, promoções e distribuir ideias, criando produtos e serviços para a satisfação das metas estabelecidas, designando trocas entre empresa e o cliente. Na visão de Kotler (2000), na relação de troca a organização beneficia-se através do dinheiro 
recebido enquanto que o cliente beneficiase por desfrutar do produto ou serviço obtido.

Para criar valor ao cliente e alcançar metas organizacionais são utilizadas combinações de ferramentas estratégicas, chamadas de Composto de Marketing. São quatro as ferramentas que fazem parte do composto de marketing, também chamado de 4P's: produto, preço, praça e promoção. $\mathrm{O}$ produto se refere ao que os profissionais de marketing oferecem ao cliente. O preço é a quantidade de dinheiro que os profissionais de marketing solicitam por aquilo que oferecem. A praça refere-se à forma como os produtos são entregues aos mercados para a troca. A promoção envolve a maneira como os profissionais de marketing informam, convencem e lembram os clientes sobre os seus produtos e serviços.

Com o mercado em constante transformação, houve a necessidade não somente da utilização de ferramentas adequadas para informar o cliente sobre os produtos e serviços que a empresa dispunha, mas, também, averiguar o comportamento do consumidor. Segundo Mowen e Minor (2003), o comportamento do consumidor é um estudo apoiado sobre as experiências diárias do consumidor, sendo essencial para a tomada de decisão gerencial e para segmentar o mercado de uma maneira mais eficaz. O comportamento do consumidor envolve questões sobre a ética e a responsabilidade social no mercado, pois o consumidor está em uma das extremidades do processo de troca. Para uma troca bem sucedida, as empresas precisam entender os fatores que influenciam nas necessidades e desejos dos consumidores, fator essencial para a satisfação desses consumidores.

Partindo do princípio de que a satisfação dos consumidores é fundamental para a existência da empresa, a problemática desse estudo atém-se ao seguinte questionamento: qual é o nível de satisfação dos clientes de uma loja materiais de construção de Itararé-SP?
Seguindo o contexto apresentado o objetivo geral do presente trabalho delimita-se em mensurar o nível de satisfação dos clientes de uma loja de materiais de construção de Itararé-SP, de acordo com a matriz de importância $x$ desempenho proposta por Slack.

Este trabalho justifica-se na tentativa de analisar a importância atribuída pelos clientes em relação ao desempenho da mesma para a possível melhoria das características avaliadas que não tiveram um resultado satisfatório na pesquisa. Essa pesquisa ainda justifica-se na possibilidade de auxiliar futuros acadêmicos que realizarão um trabalho de pesquisa de marketing em áreas semelhantes, principalmente com a utilização da metodologia proposta por Slack, já que esta foi adaptada para aplicação no segmento de materiais de construção civil.

\section{Referencial teórico}

\subsection{Marketing}

$\mathrm{O}$ marketing engloba as atividades de estabelecer preços, promoções e distribuir ideias. É criar produtos e serviços para satisfazer as metas que foram estabelecidas. Além disso, o marketing designa trocas entre a empresa ou organização e o cliente, consequentemente, trazendo benefícios a ambos (GILBERT; CHURCHILL; PETER, 2000). O marketing pode ser entendido como uma filosofia, estando além de uma atividade técnica. Para Lamb, Hair e McDaniel (2004), o marketing é uma atitude ou uma orientação do gerenciamento, realçando a satisfação do cliente. É, também, um composto de toda atividade utilizada para a implementação dessa filosofia.

Gilbert, Churchill e Peter (2000, p. 4) afirmam que "A essência do marketing é o desenvolvimento de trocas em que organizações e clientes participam voluntariamente de transações destinadas a trazer benefícios para ambos". Nessa relação de troca, a organização beneficia-se através 
do dinheiro recebido e o cliente, por desfrutar do produto ou serviço adquirido. Lamb, Hair e McDaniel (2004, p. 6) mencionam que a troca "significa que as pessoas dão algo para receber algo que elas preferem", implicando em criar valor ao cliente.

$\mathrm{Na}$ abordagem da administração mercadológica, valor implica em percepções e escolhas, não estando vinculado somente ao aspecto econômico que tange a compra de um produto (VELUDO-DEOLIVEIRA; IKEDA, 2005). Os autores apontam que o conhecimento que uma organização detém sobre os valores na perspectiva de seus clientes traz implicações para o gerenciamento de marketing. As principais implicações estão situadas na análise de mercado e segmentação, posicionamento de produtos e marcas, planejamento e desenvolvimento de produtos e marcas, e, estratégia de comunicação.

Nesse processo de adquirir conhecimento sobre os clientes, a ligação entre mercado e tecnologia possui diversas finalidades na área do marketing, pois contribuem para obtenção de conhecimentos vitais. Entender as necessidades do cliente é essencial para o sucesso do produto, e, consequentemente, do marketing (DOUGHERTY, 1996).

Para Rojo (1998), a essência do marketing está em atingir um desempenho confiável. No entanto, existem ocasiões em que as empresas ofertam serviços de forma descuidada e cometem erros que poderiam ser evitados, abalando a confiança do cliente e a imagem da empresa. Nesse sentido, a confiabilidade do consumidor está associada à possibilidade de consecução de maiores lucros.

Para auxiliar no desempenho do marketing confiável no intuito de proporcionar satisfação ao cliente, existem ferramentas adequadas. Brito, Brito e Trovão (2006) aludem que existem divergências importantes entre os principais autores do marketing sobre quais são suas ferramentas analíticas. No entanto, uma das ferramen- tas mais utilizadas é o composto de marketing.

A administração de marketing envolve o que as empresas fazem e devem fazer para criar o valor para seus clientes e alcançar seus objetivos. Em geral, essas tarefas incluem desenvolver planos e estratégias de marketing e executar atividades de marketing para implementá-los e controlá-los (GILBERT; CHURCHILL; PETER, 2000). Nesse contexto, o marketing apoia-se em um composto de ferramentas formado por produto, preço, praça e promoção (4P's).

Para Kotler (2000), decisões de composto de marketing devem ser tomadas para que se exerça influência sobre os canais comerciais, bem como sobre os consumidores finais. Levitt (1983) relaciona o desenvolvimento de produtos à solução de problemas dos clientes, ou seja, aquilo que o cliente espera de determinado produto. Para o autor, os produtos não são concebidos dentro das organizações e não se referem unicamente aos objetos que saem das fábricas. O produto torna-se alvo da satisfação do consumidor. Nesse contexto, Pereira, Borchardt e Geiger (2008) enfatizam que a melhoria da imagem de pequenas e médias empresas perante seus clientes bem como a melhor utilização de seus recursos produtivos amplia as possibilidades de negócios.

\subsection{Satisfação do consumidor}

$\mathrm{O}$ entendimento teórico e conceitual sobre o comportamento do consumidor apoia-se sobre as experiências diárias do consumidor. Mowen e Minor (2003, p. 2) afirmam que "as descobertas da pesquisa sobre o consumidor podem ser usadas também para segmentar o mercado de maneira mais eficaz".

A orientação de marketing entende que uma indústria é um processo de satisfação do cliente e não de produção de mercadoria. $\mathrm{O}$ cliente e suas necessidades fazem nascer indústrias, não patentes, matéria-prima ou habilidade de venda. Portan- 
to, "o comportamento do consumidor é definido com o estudo das unidades compradoras e dos processos de troca envolvidos na aquisição, no consumo e na disposição de mercadorias, serviços experiências e ideias" (MOWEN; MINOR, 2003, p. 3). Denota-se que na própria definição de comportamento do consumidor, a palavra troca é citada. $\mathrm{O}$ consumidor está inevitavelmente em uma das extremidades do processo de troca, onde são transferidos os recursos. O processo de troca é algo fundamental do comportamento do consumidor. Trocas ocorrem entre consumidores e empresas, sendo, às vezes, entre duas empresas caracterizando as compras industriais.

A definição do comportamento do consumidor, dada por Mowen e Minor (2003), enfatiza que o processo de trocas possui fases. Inicia-se com a aquisição, passando pelo consumo e finalizando com a disponibilidade do produto ou serviço. $\mathrm{Na}$ fase de aquisição, são analisados os fatores influenciadores nas escolhas do consumidor quanto ao produto. $\mathrm{Na}$ fase de consumo, a ênfase está na maneira como os consumidores utilizam o produto ou serviço e as experiências obtidas com o uso. A fase de disposição abarca aquilo que os consumidores fazem com os produtos quando se cansam dos mesmos, e, também, o nível de satisfação do cliente póscompra.

Cada uma das fases do processo de troca proporciona contato do cliente com o produto, em que o cliente conhece características específicas desse produto. Tontini e Sant'Ana (2007) apontam que a satisfação dos consumidores está relacionada com o atendimento de necessidades explícitas e implícitas, por meio de um conjunto de características ou atributos do produto. Portanto, torna-se importante descobrir como o desempenho dos diferentes atributos está relacionado à satisfação dos clientes. Incluso com a satisfação, a lealdade e a insatisfação do consumidor, o sentimento de "surpresa" integra os comportamentos pós-compra do consumidor (LARÁN, ROSSI, 2006). Os autores argumentam que a "surpresa" do consumidor é um fator emocional que pode ser mensurado tanto de forma positiva quanto negativa, afetando diretamente a satisfação do consumidor.

Alguns autores afirmam que a reação afetiva parece atuar de forma significativa sobre a satisfação e o encantamento do consumidor em relação aos produtos ou serviços (WESTBROOK; OLIVER, 1991; OLIVER; RUST; VARKI, 1997; VANHAMME, 2002) ou ainda na busca de relacionamentos com os clientes (VANHAMME; LINDGREEN, 2001).

Assim, a satisfação do consumidor envolve muito mais do que a simples aquisição de um produto que atenda uma necessidade. A satisfação do consumidor está atrelada à percepção que o cliente terá sobre cada um dos atributos que formarão o produto ou serviço que está sendo oferecido.

\subsection{Matriz de importância $x$ desempe- nho}

A análise de importância e desempenho é uma espécie de planilha apresentada através de uma matriz, que permite à empresa obter uma visão sobre quais características do produto ou serviço deveriam ser aperfeiçoadas para proporcionar a satisfação de seus clientes. As pesquisas de satisfação dos clientes, segundo Matzler et al. (2004, apud Tontini et al., 2005), são utilizadas para construir uma matriz bidimensional em que a importância do atributo é mostrada pelo eixo " $y$ " e o desempenho pelo eixo " $x$ ", conforme ilustrado na figura 1 : 


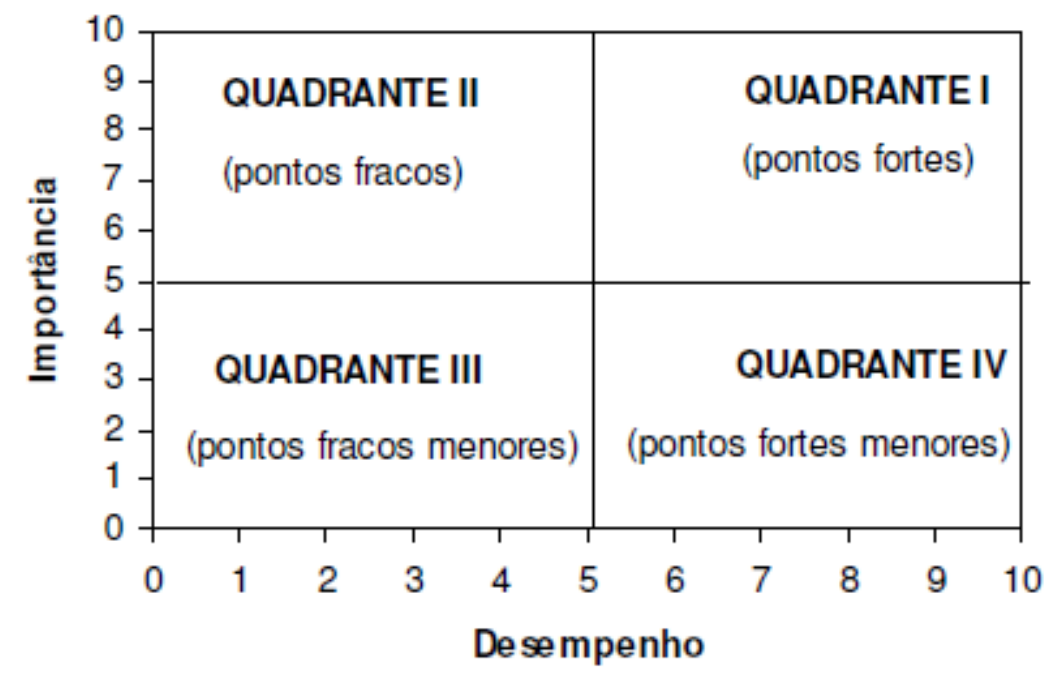

Figura 1: Matriz de Importância x Desempenho - Modelo por quadrantes

Fonte: Matzler et al. (2004, apud Tontini et al., 2004)

Os clientes avaliam a importância de determinados itens (produtos, serviços, atendimento, ambiente, entre outros) para si mesmos e o desempenho da empresa em relação a estes itens no atendimento de suas expectativas.

Para Slack (2003, p. 203), o conceito da matriz importância $\mathrm{X}$ desempenho "é a lacuna entre a classificação da 'importância' de cada objetivo de desempenho e a classificação do 'desempenho' desse objetivo que dá a guia para a prioridade". Nenhuma das duas classificações sozinhas podem estabelecer prioridades. Apenas ao colocar as duas escalas juntas poderá ser julgada a verdadeira prioridade. A proposta de Slack para a matriz importância $X$ desempenho, segmentada por zonas está apresentado na figura 2 :
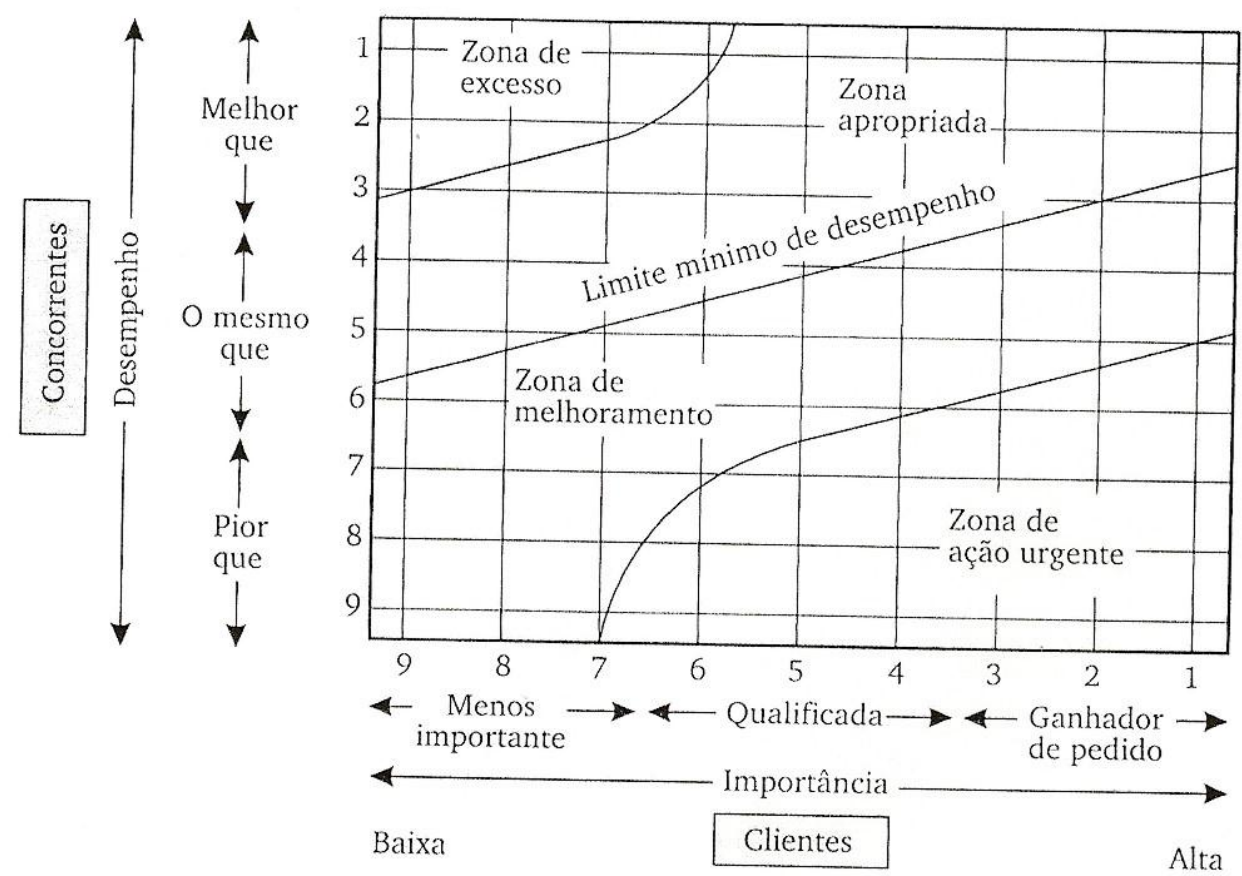

Figura 2: Matriz de Importância x Desempenho - Modelo por zonas 
Fonte: Slack (2003).

A matriz de importância e desempenho apresentada na figura 2 , considera as duas escalas desenvolvidas (importância e desempenho). A escala importância indica como os clientes enxergam a importância relativa de cada objetivo de desempenho, enquanto a escala de "desempenho" classifica as características de acordo com os níveis atingidos (SLACK, 2003).

A importância é atribuída por meio de uma escala direta ou por meio de análise de regressão, em que a importância é dada pelo coeficiente de uma regressão linear entre o desempenho do atributo e a satisfação geral com o serviço. O desempenho é atribuído por meio de escala direta, de maneira relativa à concorrência. Nenhuma das escalas é estática, sendo que ambas se classificam em posições em relação a um padrão externo dinâmico. Preferências de consumidores mudam na medida com que o mercado se desenvolve e o ambiente econômico se modifica (SLACK, 2003).

A matriz importância e desempenho é dividida em quatro zonas, segundo Slack (2003): zona "apropriada", zona de "melhoria", zona de "ação urgente" e zona de "excesso?".

A Zona "apropriada" é limitada em sua margem inferior por uma "fronteira de mínimo desempenho", ou seja, o nível de desempenho abaixo do qual a empresa, em médio prazo, não deveria permitir que a característica se localizasse. As características de desempenho que caírem nessa área devem ser consideradas satisfatórias, pelo menos a curto e médio prazo. Quando qualquer objetivo de desempenho cair abaixo do limite inferior da zona apropriada, estará sujeito a melhoramentos e estará na zona de "melhoria". Na zona de "ação urgente" encontram-se os objetivos de desempenho mais críticos. Nessa zona, o resultado do desempenho atingido é o mais baixo do que se esperava, considerando a importância para o cliente. Na zona de “excesso?”, o ponto de interrogação é im- portante, pois, quando qualquer característica situar-se nessa área, significa que o desempenho atingido é muito melhor do que o esperado, não necessariamente significando que recursos em excesso estão sendo utilizados para atingir esse nível, sendo necessário conferir se o recurso usado para atingir esse desempenho pode ser desviado para uma área mais necessitada (SLACK, 2003).

Contudo, são mantidas as hipóteses básicas que a relação entre o desempenho dos atributos e a satisfação é linear e que a importância e o desempenho são dimensões independentes. Ocorre, porém, que a relação entre o desempenho do atributo e a satisfação gerada é mais complexa, não apenas não linear, mas também assimétrica. A importância se altera de acordo com o desempenho, trazendo um maior grau de complexidade na análise das oportunidades de melhoria.

\section{Metodologia}

A presente pesquisa teve uma abordagem quantitativa com aplicação de um questionário, cujo recorte de estudo para aplicação foi uma única loja do setor de materiais de construção do município de Itararé-SP

A pesquisa tomou por base populacional os clientes cadastrados no sistema que formam a base de dados da empresa, totalizando 1886 clientes, sendo 1669 cadastros físicos e 217 jurídicos. Foram distribuídos questionários a todos os clientes com cadastro de pessoa física, sendo que 200 clientes responderam o questionário, compondo a amostra desse estudo. A pesquisa foi realizada com o intuito de verificar a satisfação dos clientes quanto ao atendimento, produtos disponíveis e serviços (entrega de material de construção) da loja.

A coleta dos dados foi realizada por meio de um questionário. Este foi desenvolvido seguindo a proposição de Slack 
(2003), selecionando algumas características para análise na matriz de desempenho $\mathrm{X}$ importância. O questionário foi composto por um total de oito questões, das quais seis destinam-se à identificação do perfil do cliente da loja de materiais de construção e duas referem-se às características avaliadas na matriz de importância $X$ desempenho. As questões de identificação dos clientes referem-se a local de residência, sexo, idade, estado civil, renda mensal e frequência com que adquire produtos na loja.

As variáveis (ou características) que compunham o questionário para avaliação da satisfação do consumidor representam atributos que a loja de materiais de construção apresenta aos clientes ou atributos dos serviços prestados pelo estabelecimento. Todas as variáveis foram escolhidas de forma a permitir uma avaliação da empresa, sendo que o resultado de cada variável foi submetido à matriz de análise importância X desempenho. As variáveis selecionadas para a presente investigação foram:

- Localização;

- Ambiente: aparência, higiene e conforto;

- Diversidade de produtos;
- Exposição dos produtos;

- Marca dos produtos oferecidos;

- Preço;

- Promoções e divulgação;

- Atendimento no balcão;

- Atendimento via telefone;

- Entrega domiciliar;

- Estacionamento;

Além dessas variáveis, foi investigada a "confiabilidade da empresa". No intuito de mensurar a consistência interna do questionário utilizado, foi calculado o coeficiente Alfa de Cronbach, para as escalas de satisfação e importância. Para o conjunto de 12 características que compõem a escala de satisfação, obteve-se um Alfa de Cronbach de 0,918 e para o conjunto de 12 características que formam a escala de importância o índice de Alfa de Cronbach foi de 0,917 , sendo, em ambos os casos considerados bastante satisfatórios.

Para um melhor ajuste entre as características consideradas no questionário, calculou-se o Alfa de Cronbach considerando a exclusão de uma das características. A tabela 1 mostra os resultados para os Alfas de Cronbach considerando a exclusão de casa uma das características, tanto para satisfação quanto para importância:

Tabela 1: Alfa de Cronbach considerando a exclusão das características

\begin{tabular}{lcc}
\hline \multicolumn{1}{c}{ Características ou variáveis } & $\begin{array}{c}\text { Alfa de Cronbach se o item for } \\
\text { excluído - escala de satisfação }\end{array}$ & $\begin{array}{c}\text { Alfa de Cronbach se o item for ex- } \\
\text { cluído - escala de importância }\end{array}$ \\
\hline Localização da loja & 0,906 & 0,910 \\
Ambiente & 0,913 & 0,909 \\
Diversidade de produtos & 0,908 & 0,907 \\
Exposição dos produtos & 0,911 & 0,906 \\
Marca dos produtos oferecidos & 0,911 & 0,909 \\
Preços & 0,916 & 0,914 \\
Condições de pagamento & 0,915 & 0,908 \\
Promoções e divulgação dos produtos & 0,908 & 0,908 \\
Atendimento no balcão & 0,909 & 0,908 \\
Atendimento via telefone & 0,907 & 0,908 \\
Entrega domiciliar & 0,916 & 0,912 \\
Estacionamento & 0,918 & 0,916 \\
\hline
\end{tabular}


Denota-se que, com a exclusão de qualquer das características, tanto na escala de satisfação quanto na escala de importância, não é possível elevar o índice do Alfa de Cronbach para um valor mais ele- vado do que se considerado o conjunto das 12 características.

Para medir cada uma das variáveis, utilizou-se uma escala de resposta do tipo Likert, composta por cinco graus de satisfação, conforme apresentado na tabela 2 :

Tabela 2: Escala de resposta para satisfação

\begin{tabular}{ll}
\hline Resposta & Correspondência com o grau de satisfação \\
\hline 1 & Muito insatisfeito \\
2 & Insatisfeito \\
3 & Indiferente \\
4 & Satisfeito \\
5 & Muito satisfeito \\
\hline
\end{tabular}

O mesmo padrão de respostas foi seguido para medir o grau de importância das características. A tabela 3 apresenta as escalas de respostas utilizadas na mensuração da importância:

Tabela 3: Escala de resposta para importância

\begin{tabular}{ll}
\hline Resposta & Correspondência com o grau de importância \\
\hline 1 & Nada importante \\
2 & Pouco importante \\
3 & Indiferente \\
4 & Importante \\
5 & Muito importante \\
\hline
\end{tabular}

O questionário passou pela análise de um profissional da área da linguística e teve a aplicação do teste piloto em 15 de abril de 2011. A coleta de dados foi realizada por um período de dois meses, iniciando em 16 de maio de 2011 a 16 de julho de 2011.

A análise dos dados deu-se por meio de estatística descritiva, desenvolvida no programa Microsoft Excel 2010. Além da estatística descritiva, a matriz de desempenho X importância foi analisada com o desenvolvimento de tabelas de correlação e gráficos de dispersão, enquanto nos dados referentes ao perfil do consumidor enfatizou-se os cálculos de soma, média e desvio padrão.

\section{Resultados e discussão}

A análise dos dados está baseada na obtenção dos dados referentes aos 200 questionários respondidos. A primeira questão do questionário aplicado, composto de oito questões, refere-se a cidade onde o consumidor reside. No gráfico 1 apresenta-se de forma geral, a porcentagem das cidades em que os clientes do estabelecimento residem: 


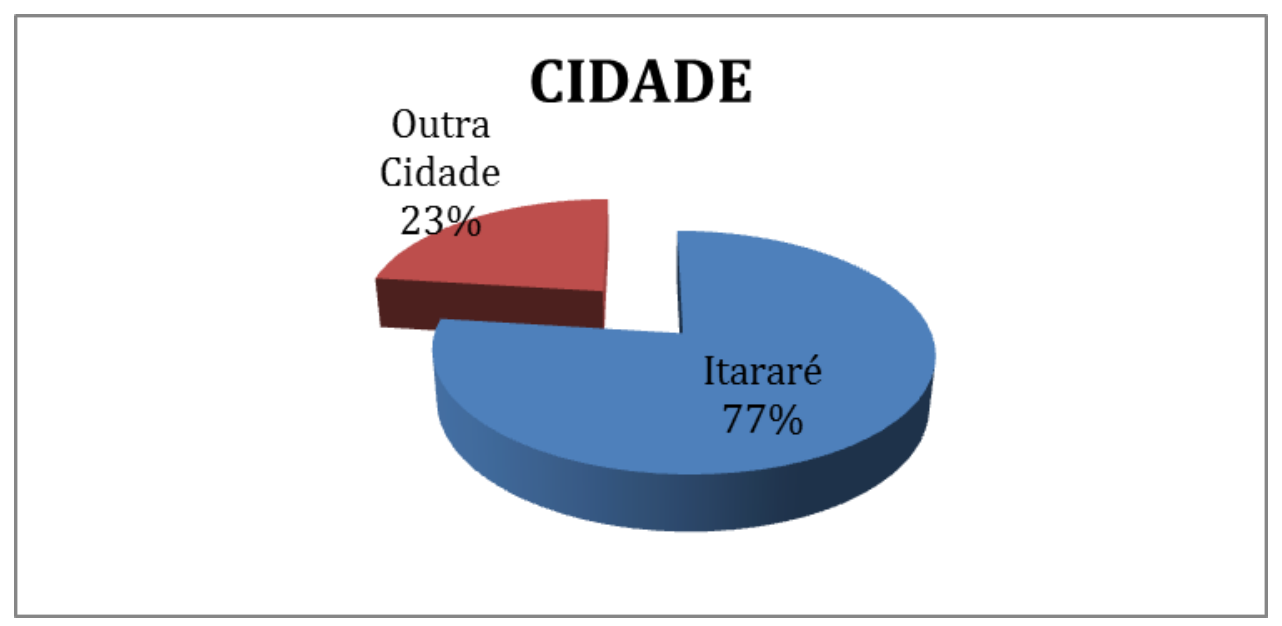

Gráfico 1: Cidades de residência dos clientes (abordagem geral)

Observa-se que a maioria dos consumidores reside na própria cidade em que a loja está situada - Itararé (77\%), e $23 \%$ consumidores residem em "outra cidade", porém, por motivos diversos e/ou eventualidade adquirem produtos na loja em Itararé-SP.

No gráfico 2, apresenta-se em detalhes as "outras cidades" em que os clientes são residentes:

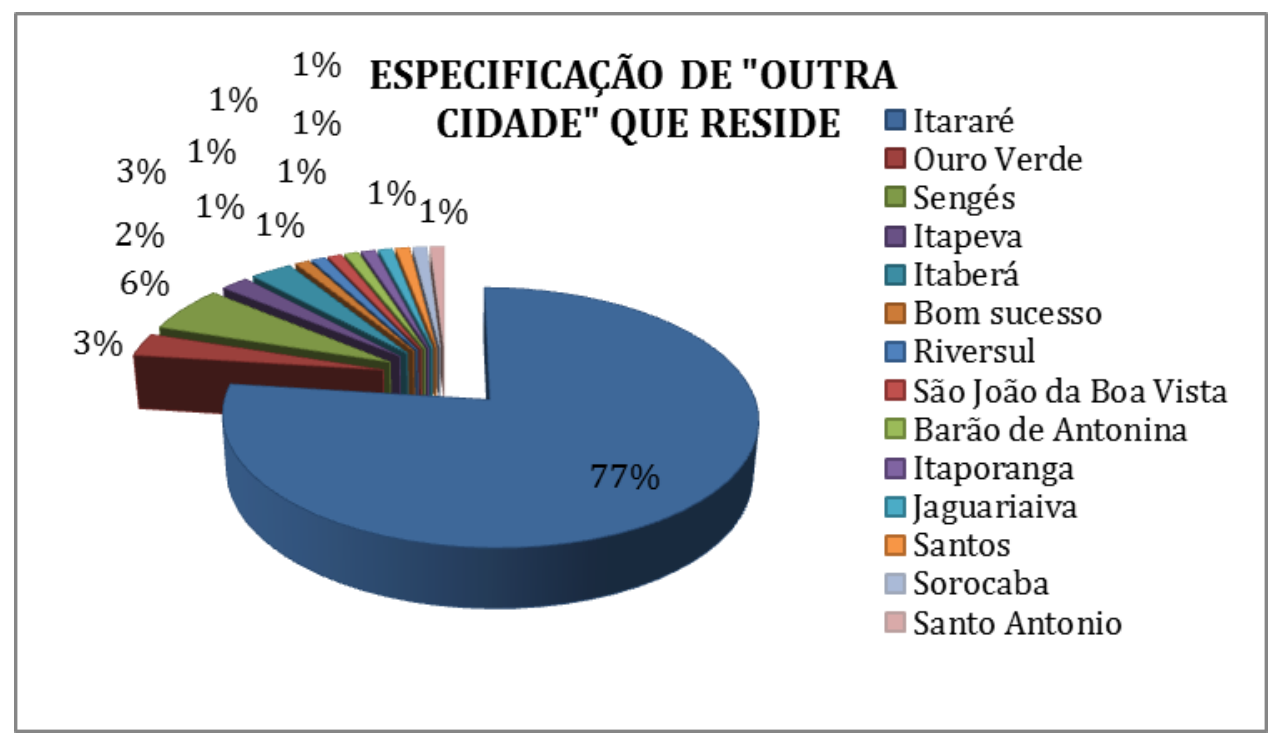

Gráfico 2: Especificação de "outra cidade" que residem os clientes

Percebe-se que a maioria dos clientes reside na cidade em que se localiza a loja. As outras cidades de residência dos clientes obteve variação, sendo que os municípios de Ouro Verde, Sengés, Itapeva e Itaberá merecem destaque, pois juntas contabilizam 14\% do índice cotado como "outras cidades".

Os consumidores residentes em Itararé adquirem os produtos da loja devi- do à variedade de produtos, confiança e comodidade da entrega. Os consumidores não residentes em Itararé se deslocam de suas cidades para adquirir os produtos da loja devido a variedade de produtos e marcas, confiança e pela comodidade com a entrega.

Nos casos em que a cidade de residência do consumidor fique fora do alcance da entrega da empresa como, por 
exemplo, a cidade de Santos localizada no litoral paulista, pode-se considerar que são clientes esporádicos e estavam de férias em Itararé e tiveram algum tipo de imprevisto,

A segunda questão do questionário aplicado refere-se ao gênero dos clien- considerando o período de aplicação do questionário, necessitando assim, realizar a aquisição de algum produto.

tes pesquisados. O gráfico 3 apresenta os dados sobre gênero:

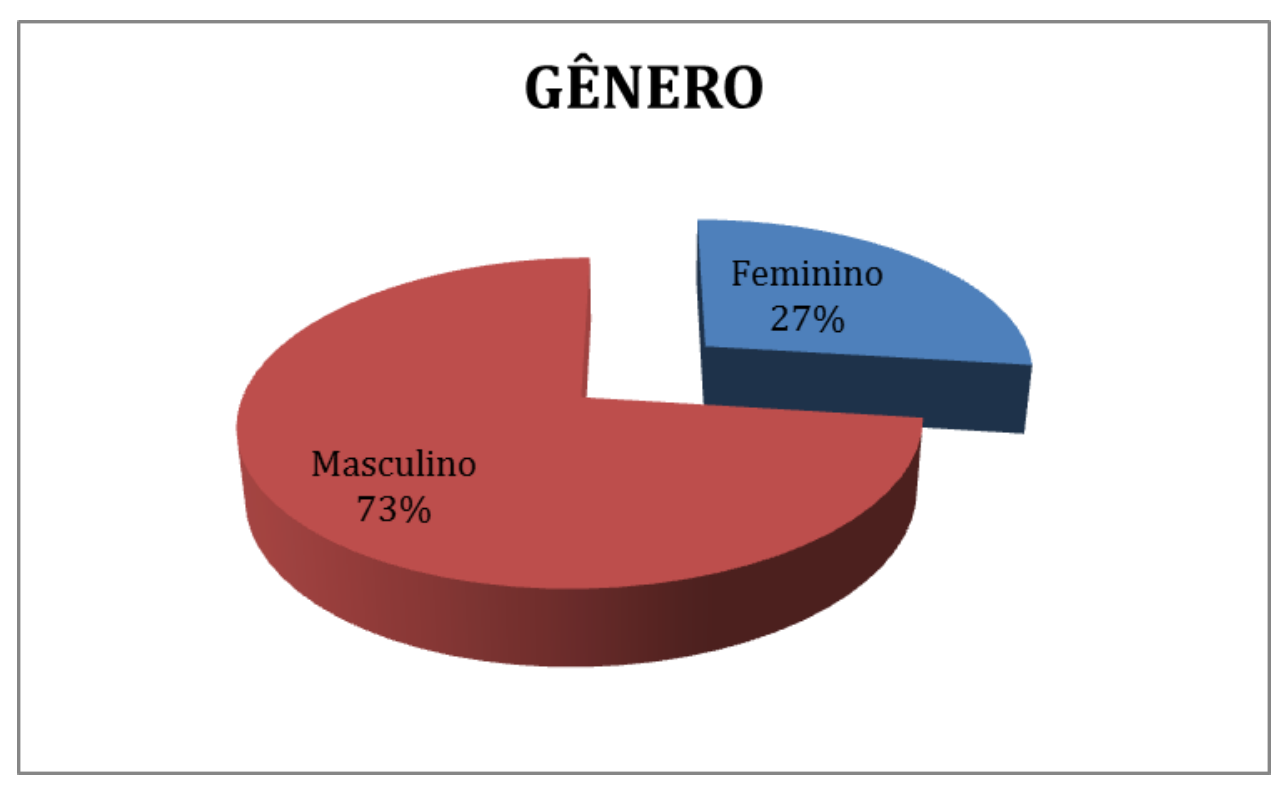

Gráfico 3: Gênero do consumidor

Para o quesito gênero tem-se uma maioria de $73 \%$ do sexo masculino, considerando construtores, engenheiros civis, arquitetos, pedreiros, auxiliares, mestres de obras, financiadores e chefes de família que estão reformando ou construindo.

A porcentagem que representa o sexo feminino, mesmo sendo a minoria, não é irrelevante (27\%). Considerando que as mulheres estão cada vez mais inseridas no mercado de trabalho, inclusive nos campos considerados "masculinos", a porcentagem obtida é justificável.

Essas consumidoras podem ser engenheiras civis, arquitetas ou decoradoras de residências (que atuam como profissionais ou como hobby), auxiliar de obras ou ainda, dona de casa ou mãe de família.

A terceira questão do questionário indaga sobre as idades dos consumidores da loja. Os dados são mostrados no gráfico 4: 


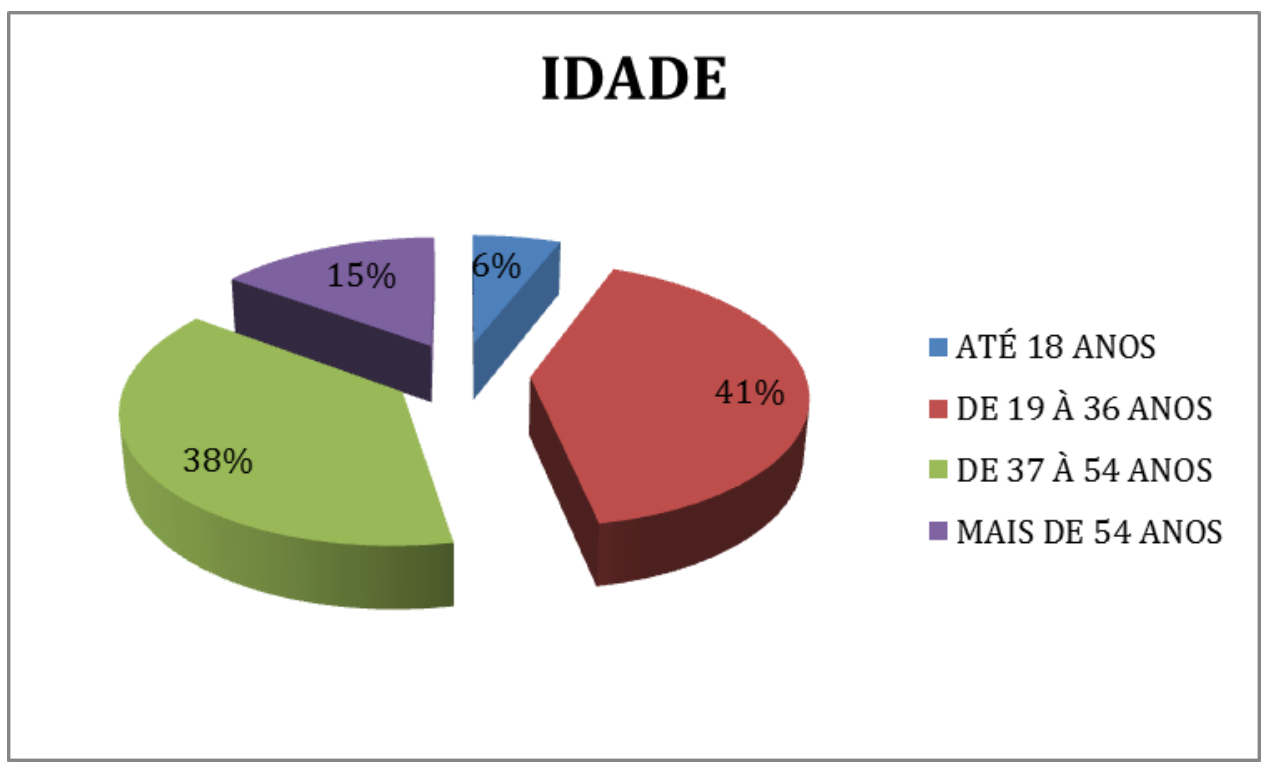

Gráfico 4: Idade

Os consumidores com até 18 anos representam a minoria na pesquisa realizada. Pode-se considerar que esses consumidores são adolescentes, possivelmente de baixa renda, que precisam trabalhar como auxiliar de obras para sustentar ou ajudar nas despesas da casa. Nesse caso, o adolescente receberia a solicitação para se deslocar até a loja e adquirir produtos necessitados na obra que está trabalhando.

Os consumidos com a faixa etária entre 19 e 36 anos, podem ser considerados os próprios trabalhadores das obras, arqui- tetos, engenheiros civis, mestres de obras, chefe de família e até recém-casados adquirindo produtos para a construção ou reforma de sua casa ou local de trabalho.

Consumidores entre 37 e 54 anos também podem ser os próprios trabalhadores das obras, assim como os consumidores com mais de 54 anos, podendo estar arcando financeiramente as obras e/ou reformas.

A quarta questão do questionário refere-se ao estado civil dos consumidores. O gráfico 5 apresenta cada uma das porcentagens indicadas:

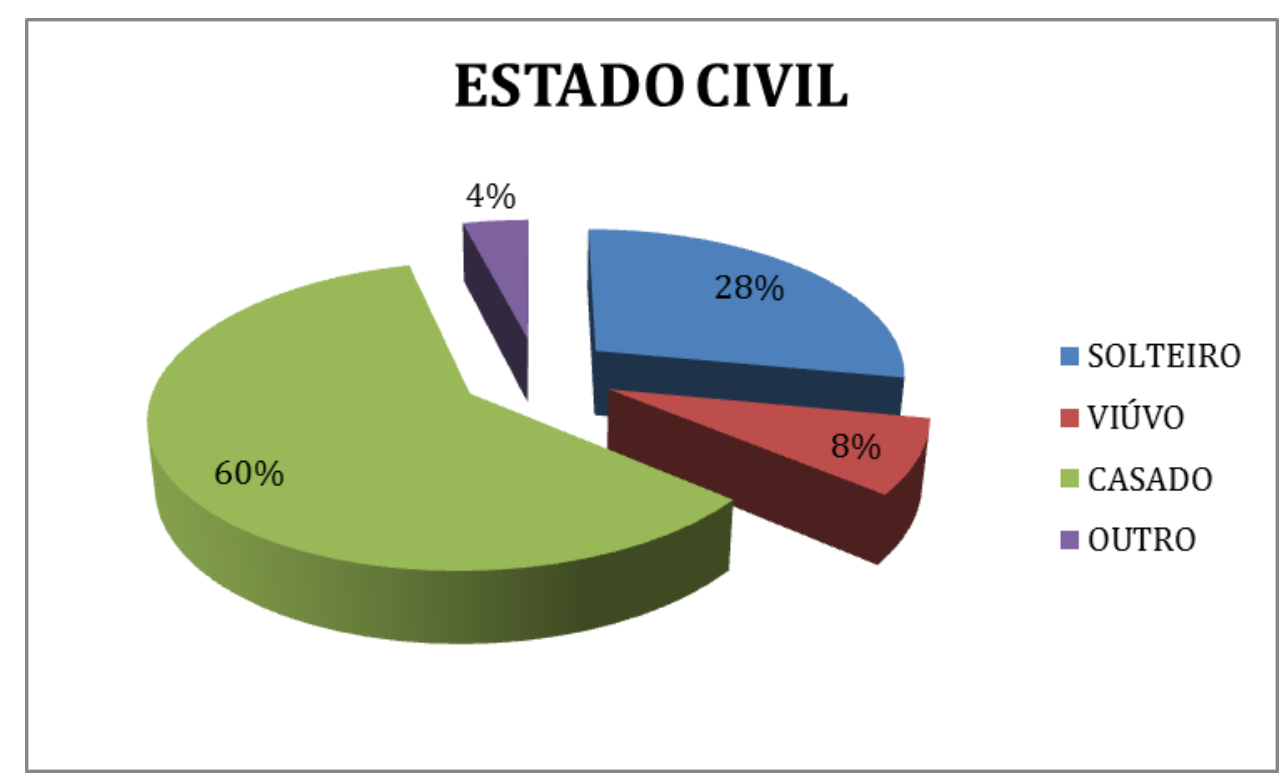


Gráfico 5: Estado Civil

Evidenciou-se que a maioria dos consumidores da loja de materiais de construção é casada (60\%). Nessa porcentagem se enquadram recém-casados que estão construindo ou reformando o local onde será o alicerce de sua família, os pais de família que trabalham em obras no ramo construtor ou em seus próprios projetos.

Os consumidores solteiros somam $28 \%$. Já os clientes viúvos representam que os $8 \%$, sendo estes, possivelmente pessoas mais idosas, pais de família, chefes de obras ou engenheiros.

Os consumidores que consideraram "outro" como o seu estado civil somam $4 \%$. Estes podem ser divorciados ou que vivem em relacionamento de união estável.

A quinta pergunta realizada aos clientes refere-se à renda mensal dos consumidores. Os dados são apresentados no gráfico 6:

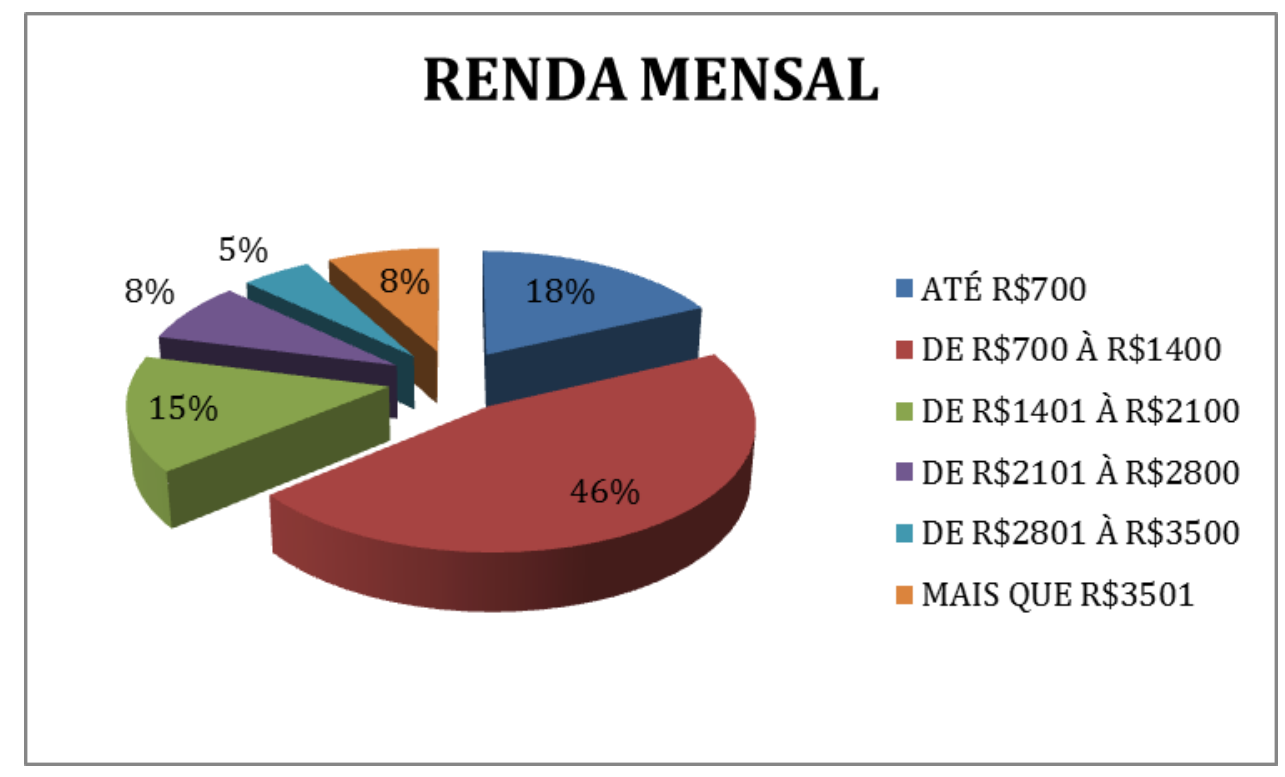

Gráfico 6: Renda mensal

A maioria dos consumidores pesquisados $(46 \%)$ possui renda mensal entre $\mathrm{R} \$ 700,00$ e $\mathrm{R} \$ 1.400,00$. Em seguida, com $18 \%$, estão os consumidores com renda mensal de até $\mathrm{R} \$ 700,00$, supondo que sejam os auxiliares na obra, pais de família e pessoas construindo e/ou reformando.

Consumidores que fazem parte dos $15 \%$ com renda mensal entre $\mathrm{R} \$ 1.401,00$ à $\mathrm{R} \$ 2.100,00$ podem ser pais de família, mestres de obras engenheiros civis, arquitetos. Já os consumidores classificados com a menor porcentagem $(8 \%$;
$8 \%$ e $5 \%$ do total pesquisado), possuem rendas entre $\mathrm{R} \$ 2.101,00$ à $\mathrm{R} \$ 2.800,00$; acima de $R \$ 3.501,00$ e entre $R \$ 2.801,00$ à $\mathrm{R} \$ 3.500,00$, respectivamente, possivelmente enquadrem-se como engenheiros civis, arquitetos, pais de família, empresários e financeiros das obras.

A sexta questão do questionário aplicado refere-se a frequência em que os consumidores pesquisados realizam suas compras na loja. Os dados são apresentados no gráfico 7: 


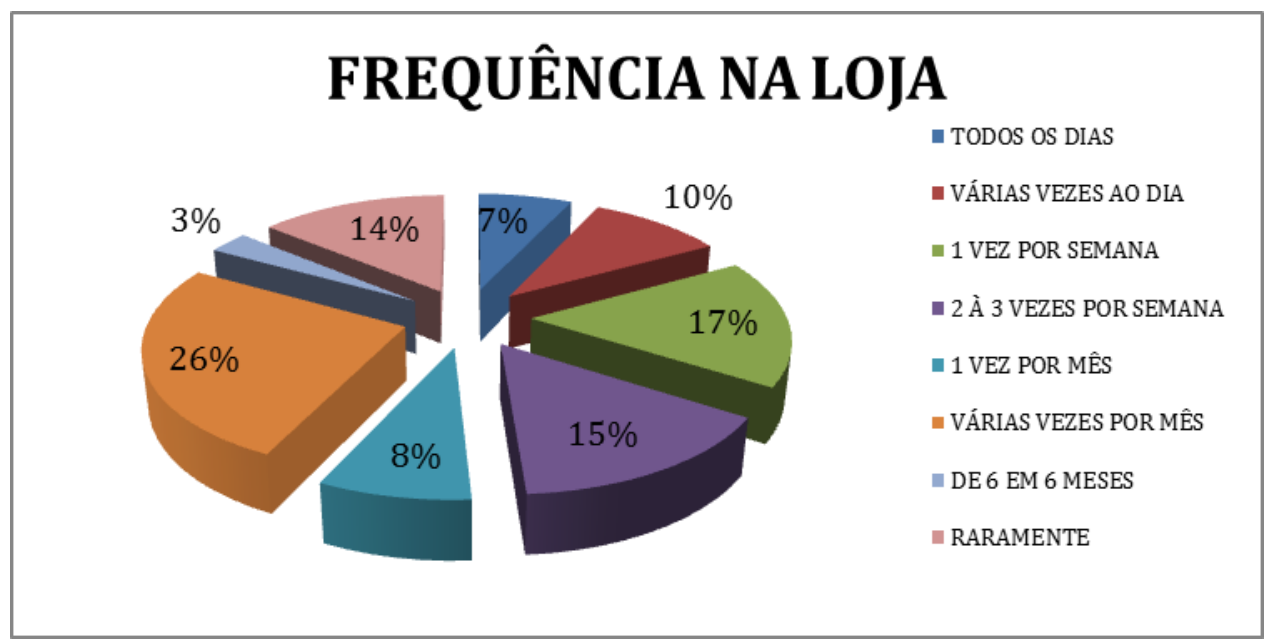

Gráfico 7: Frequência dos consumidores à loja

Consumidores que frequentam a loja todos os dias e várias vezes ao dia contabilizam $7 \%$ e $10 \%$, respectivamente, são consumidores que estão informados a respeito da obra e ficaram responsáveis pela aquisição da mercadoria necessária para a construção naquele determinado momento.

Os clientes que frequentam o estabelecimento "uma vez por semana" e de "2 à 3 vezes por semana" representam 17\% e $15 \%$, respectivamente. Supõe-se que são os mestres de obra, quando necessitam de algum produto mais específico.

Os frequentadores de "uma vez ao mês" e "várias vezes ao mês" representam $8 \%$ e $26 \%$. Já aqueles consumidores que frequentam pouco o estabelecimento, como de "seis em seis meses" ou "raramente" somam $3 \%$ e $14 \%$, respectivamente. Nesse caso, as compras são realizadas com menor frequência, representando um possível imprevisto em ambiente familiar ou no canteiro de obra.

As questões, 7 e 8 do questionário referem-se a importância e o desempenho que os consumidores avaliaram determinados itens da empresa, com a finalidade de formar a matriz de importância X desempenho.

No decorrer da análise dos dados, os itens avaliados pelos consumidores quanto a importância e o desempenho seguem a seguinte ordem de numeração:

1- Localização da loja;

2- Ambiente (aparência, higiene, conforto);

3- Diversidade de produtos;

4- $\quad$ Exposição dos produtos;

5- $\quad$ Marcas dos produtos oferecidos;

6- Preços;

7- $\quad$ Condições de pagamento;

8- Divulgação dos produtos

9- $\quad$ Atendimento no balcão;

10- Atendimento via telefone;

11- Entrega domiciliar;

12- Estacionamento.

A localização da loja refere-se justamente ao local onde a loja de materiais de construção está inserida na cidade.

Ambiente (aparência, higiene e conforto) é uma variável para o consumidor avaliar o ambiente interno e externo da loja. As variáveis possibilitam mensurar se o ambiente do estabelecimento possui aparência adequada, está bem organizada e apresenta fácil acesso ao produto que o cliente pretende adquirir, limpeza da loja, dos móveis e se essa higienização é constante.

Quanto a diversidade dos produtos, o consumidor avalia se todos os itens que está necessitando são encontrados no estabelecimento. Ao apresentar uma distribuição adequada dos produtos e prateleiras organizadas, o consumidor encontra com 
mais facilidade o produto desejado. Com uma variedade de marcas de produtos disponíveis, os consumidores possuem um leque maior de opções e fazer as escolhas que os satisfaçam no momento da aquisição do produto.

No quesito preço, os consumidores avaliaram se os produtos oferecidos pelo estabelecimento estão adequados ao proposto pelo mercado. As condições de pagamento foram avaliadas de acordo com a heterogeneidade de condições. A loja oferece aos clientes as condições de pagamento "a vista", em três vezes, via boleto bancário, por cartão de crédito, e financiamento. A variável divulgação dos produtos refere-se à promoção e à forma com que os produtos são divulgados aos consumidores.
Quanto ao atendimento no balcão e via telefone os consumidores avaliaram o modo como foram atendidos pelos funcionários da loja no momento da aquisição de algum produto. A entrega domiciliar refere-se ao modo com que os motoristas entregaram as mercadorias, o tempo de espera e se os itens foram entregues conforme solicitado previamente. Já o estacionamento foi avaliado conforme a disponibilidade de vagas, número de vagas com cobertura e sem cobertura.

Para avaliar a concentração e dispersão das respostas tanto dos itens relativos à importância quanto a satisfação dos clientes, realizou-se o cálculo da estatística descritiva, desvio padrão e correlação. A tabela 4 apresenta os resultados:

Tabela 4: Estatística descritiva, desvio padrão e correlação

\begin{tabular}{|c|c|c|c|c|c|c|c|}
\hline \multirow[b]{2}{*}{ Variável } & \multirow[b]{2}{*}{ Correlação } & \multicolumn{3}{|c|}{ Satisfação } & \multicolumn{3}{|c|}{ Importância } \\
\hline & & Somatório & Média & $\begin{array}{l}\text { Desvio } \\
\text { Padrão }\end{array}$ & Somatório & Média & $\begin{array}{l}\text { Desvio } \\
\text { padrão }\end{array}$ \\
\hline Localização da loja & 0,09 & 830 & 4,15 & 0,88 & 832 & 4,16 & 0,87 \\
\hline Ambiente (aparência, higiene, conforto) & 0,02 & 840 & 4,2 & 0,68 & 848 & 4,24 & 0,67 \\
\hline Diversidade de produtos & 0,05 & 872 & 4,36 & 0,74 & 850 & 4,25 & 0,74 \\
\hline Exposição de produtos & 0,05 & 860 & 4,3 & 0,69 & 836 & 4,18 & 0,73 \\
\hline Marca dos produtos oferecidos & 0,12 & 876 & 4,38 & 0,73 & 848 & 4,24 & 0,68 \\
\hline Preços & $-0,01$ & 802 & 4,01 & 0,96 & 828 & 4,14 & 0,90 \\
\hline Condições de pagamento & $-0,02$ & 806 & 4,03 & 0,93 & 836 & 4,18 & 0,89 \\
\hline Divulgação dos produtos & 0,01 & 794 & 3,97 & 0,82 & 824 & 4,12 & 0,82 \\
\hline Atendimento no balcão & 0,00 & 814 & 4,07 & 0,92 & 834 & 4,17 & 0,89 \\
\hline Atendimento via telefone & 0,05 & 792 & 3,96 & 0,90 & 868 & 4,34 & 0,83 \\
\hline Entrega domiciliar & 0,12 & 900 & 4,5 & 0,69 & 900 & 4,5 & 0,69 \\
\hline Estacionamento & 0,05 & 904 & 4,52 & 0,63 & 900 & 4,5 & 0,66 \\
\hline
\end{tabular}

Dos mil pontos possíveis no somatório, a empresa atinge os 900 pontos na variável entrega domiciliar para a satisfação dos clientes e exatamente a mesma pontuação na importância atribuída pelos clientes para a variável. A variável Estacionamento atinge 904 pontos para a satisfação e 900 pontos na importância.

Isso demonstra que a variável estacionamento é um item que não necessita de me- lhorias, já que a satisfação dos clientes está acima da média de importância atribuída para a variável pelos clientes. Os itens de atendimento via telefone e divulgação dos produtos apresentaram as menores pontuações.

Em síntese, os itens de Diversidade de produtos, Exposição dos produtos e Marca dos produtos oferecidos são as variáveis que apresentam maior satisfação ou desempenho em relação à importância atribuída pelos clientes para cada variável. 
As variáveis Localização da loja, Ambiente, Estacionamento e Entrega domiciliar apresentaram pontuação iguais ou equivalentes para o desempenho e importância, sendo que a diferença mais significativa entre os itens é de 0,04. As variáveis em que predomina a importância do item em relação a satisfação do cliente com o desempenho da loja são: Preços, Condições de pagamento, Divulgação dos produtos, Atendimento no balcão, Atendimento via telefone. As menores notas quanto a satisfação dos clientes foram atribuídas para as variáveis divulgação dos produtos e Atendimento via telefone.

O desvio padrão decorrente de todas as variáveis sugere uma elevada taxa de variação nas respostas, ou seja, enquanto que um cliente atribui um valor próximo a cinco para a representação da sua satisfação ou importância de uma variável, o outro cliente atribuiu um valor próximo a um (considerando uma escala de Likert de um a cinco).

A correlação de Pearson pode apresentar uma variação entre 1 e -1 (um positivo e um negativo). Se a correlação positiva for evidente, entende-se que uma variável aumenta na medida em que outra também aumenta. No caso de correlação negativa, enquanto que uma variável aumenta a outra diminui. No caso estudado, cada variável foi correlacionada com as notas atribuídas pelos clientes para o desempenho e para a importância. O resultado demonstra que as variáveis não apresentam correlação significativa entre si, visto que para uma correlação ser considerada significativamente forte o resultado deve estar próximo ou acima de 0,7 .

A variável Confiabilidade da empresa foi investigada somente a âmbito de desempenho, sendo que a empresa foi considerada por seus clientes como uma empresa confiável, atingindo 4,58 pontos dos cinco possíveis. A confiabilidade foi uma das variáveis que apresentou menor desvio padrão $(0,68)$, ou seja, uma maior uniformidade nas respostas.

Os dados para as 12 variáveis supramencionadas, tanto para o desempenho mensurado pelos clientes quanto para a importância, serão apresentados no gráfico de dispersão 8, seguindo o modelo por zonas de desempenho propostas por Slack (2003):

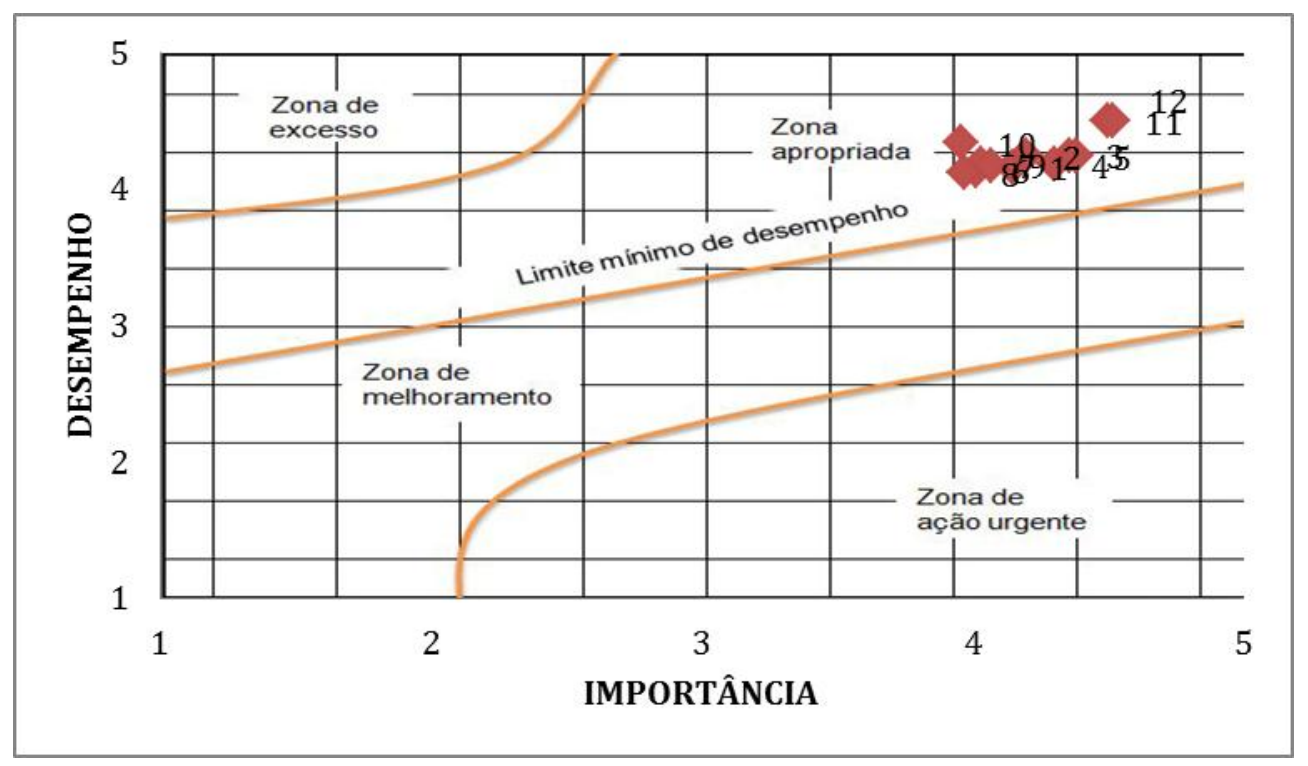

Gráfico 8: Matriz desempenho X importância, seguindo as zonas de desempenho tribuídas somente na zona apropriada, ou

Observa-se que todas as variáveis investigadas durante a pesquisa foram dis- seja, todos os itens avaliados (importância e desempenho) foram considerados satisfa- 
tórios para a empresa em médio e longo prazo. A partir do gráfico 8 e atrelando às definições de cada zona proposta por Slack (2003), todas as variáveis tiveram desempenho satisfatório, pelo menos a curto e médio prazo.

Como a matriz de importância $\mathrm{x}$ desempenho obteve notas inseridas somente na zona apropriada, foi elaborada uma nova matriz, com ajuste (aproximação) dos eixos para que as variáveis adquirissem maior distribuição ou afastamento, com a finalidade de melhorar a análise de cada variável. Com o ajuste dos eixos é possível avaliar as variáveis sob uma nova percepção. Os dados com aproximação do eixo estão apresentados no gráfico 9:

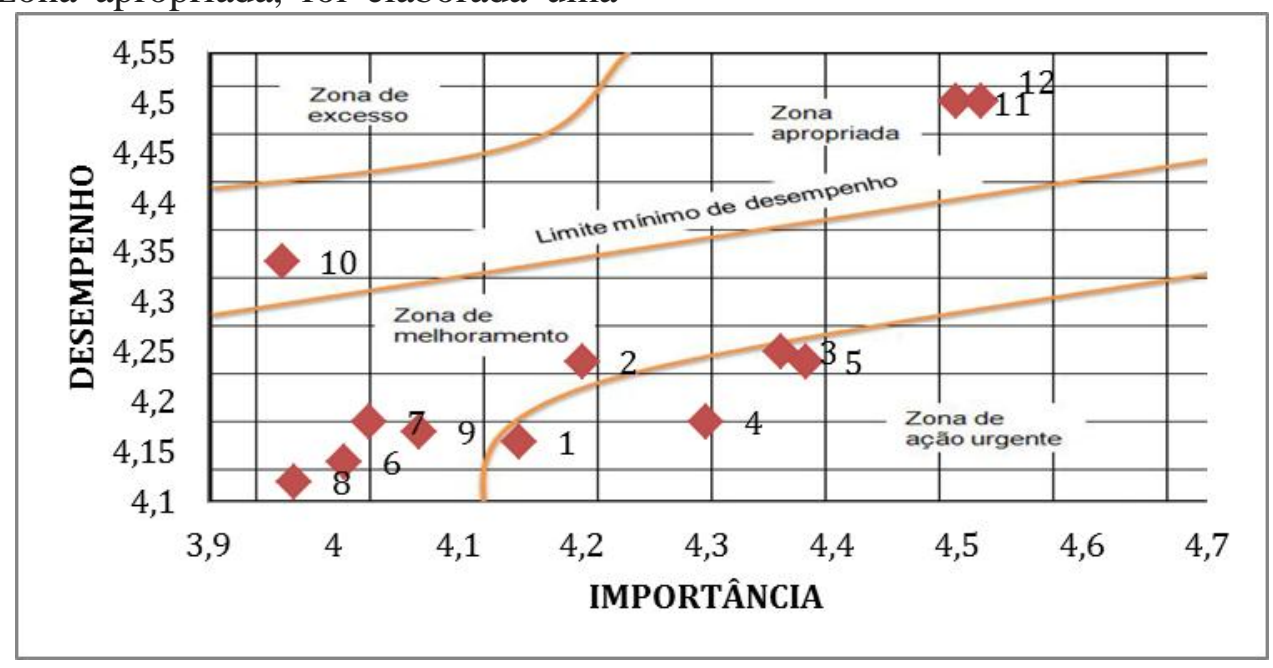

Gráfico 9: Matriz desempenho X importância, seguindo as zonas de desempenho com ajustes nos eixo

Segundo Slack (2003), a Matriz desempenho $\mathrm{X}$ importância possui quatro zonas. Após a aproximação dos eixos, obteve-se o enquadramento das variáveis em três zonas, enquanto que no gráfico 8 (sem aproximação dos eixos) o enquadramento das variáveis permaneceu somente em uma zona.

Denota-se no gráfico 9 que os itens 10,11 e 12 (Atendimento via telefone, Entrega domiciliar e o Estacionamento) encontram-se na zona apropriada. Dentre as 12 variáveis, essas três apresentam a avaliação mais favorável perante os clientes. Isso significa que esses três itens são considerados satisfatórios para a empresa no médio e longo prazos.

$\mathrm{Na}$ zona de melhoramento, tem-se os itens 2, 6, 7, 8 e 9 sendo respectivamente: Ambiente, Preço, Condições de pagamento, Divulgação dos produtos e Atendimento no balcão. Denota-se que os consumidores não estão totalmente satisfeitos com esses itens, sendo que esses itens pre- cisam de melhorias ou investimentos por parte da empresa pesquisada. Como exemplo, a variável Ambiente pode sofrer melhorias de forma a aumentar o conforto do consumidor; os Preços podem ser ajustados conforme a necessidade e condições de mercado, promoções podem ser realizadas com maior efetividade, entre outros. No quesito Condições de Pagamento, a empresa busca a realização de melhorias, incluindo novas modalidades de pagamento, como a instalação de máquinas para cartões de crédito e débito. Já a Divulgação dos produtos poderiam ser no formato de panfletos, emissoras de rádios locais, jornais e revistas. O Atendimento no balcão poderia ser melhorado através de treinamentos e capacitações.

$\mathrm{Na}$ zona de ação urgente tem-se aqueles itens que tiveram resultados abaixo do desempenho esperado pela organização. Encontram-se as variáveis 1, 3, 4 e 5 que são: Localização da loja, Diversidade de produtos, Exposição dos produtos e Mar- 
cas dos produtos. São itens que necessitam de mudanças mais urgentes. A Localização da Loja é o único item com uma maior dificuldade de ser alterada ou melhorada; a Diversidade de produtos pode ser melhorada com o aumento da variedade de produtos disponíveis; a Exposição dos produtos pode ser alterada de forma a facilitar a procura e o acesso do consumidor ao produto desejado; do mesmo modo, a Diversi- dade e as Marcas dos produtos podem ser ampliadas, contemplando várias linhas de produtos e abarcando qualidade e diversidade.

De forma sintética e de fácil visualização, os dados da matriz de importância $\mathrm{X}$ desempenho, apresentada no gráfico de dispersão com aproximação dos eixos são apresentados na figura 3 :

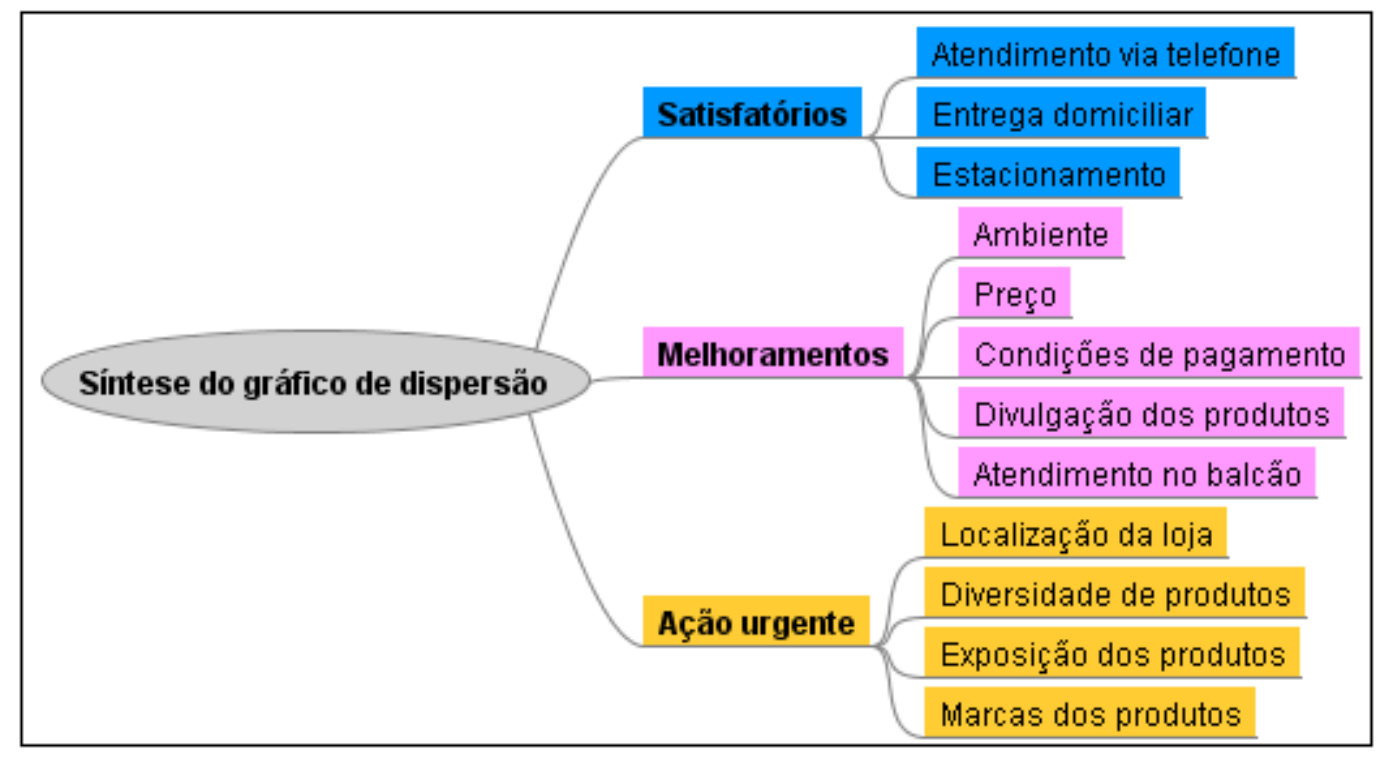

Figura 3: Síntese do gráfico de dispersão (com eixos ajustados)

Nesse formato de visualização, é possível observar três variáveis enquadradas como satisfatórias, cinco variáveis na zona de melhoramentos e quatro variáveis na zona de ação urgente.

Como forma de melhorar a visualização da distribuição ou aproximação de cada variável investigada, apresenta-se no gráfico 10 a matriz de importância X desempenho no formato proposto por Matzler (2004), ou seja, através de quadrantes:

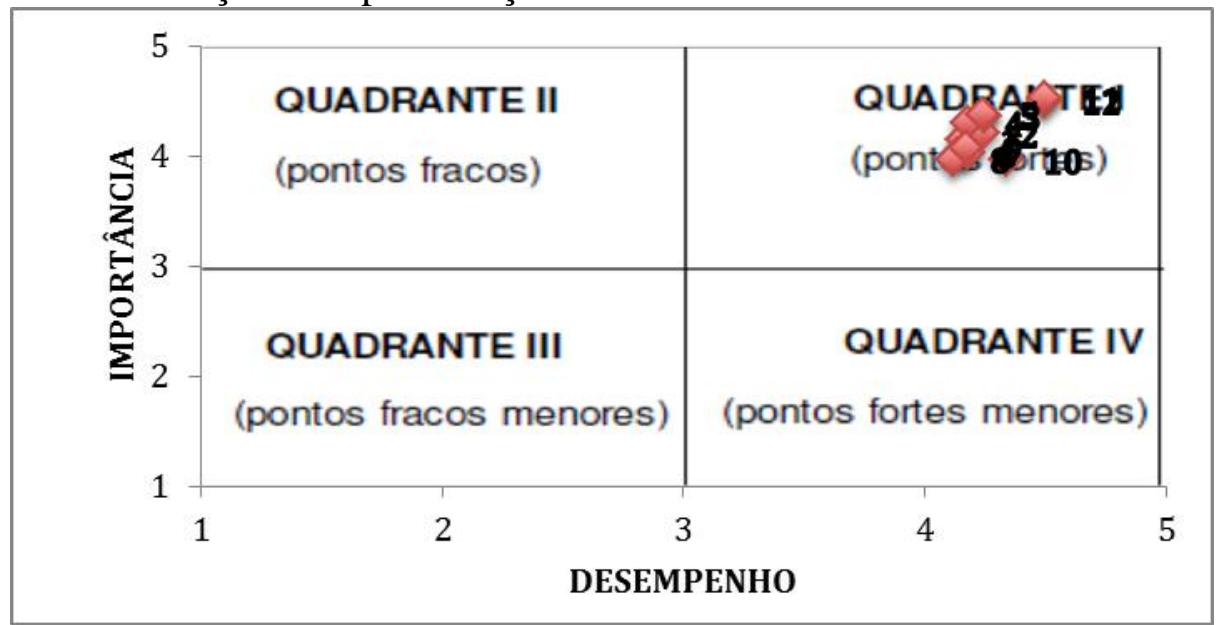


Gráfico 10: Matriz importância X desempenho por quadrantes

Observa-se que, como no gráfico de dispersão (sem ajustes dos eixos), todas as variáveis investigadas durante a pesquisa foram distribuídas somente no mesmo quadrante, neste caso, no quadrante I, ou seja, a empresa apresenta aproveitamento "satisfatório" relacionado à importância e desempenho de todos os itens avaliados.

A análise apresentada condiz com as análises de satisfação realizada para cada variável individualmente (tabela 3 ), pois a empresa não apresentou nenhuma nota com índice insatisfatório. Como a matriz de importância $\mathrm{x}$ desempenho por quadrante obteve notas inseridas somente no quadrante I, foi elaborada uma nova matriz, com foco apenas para o único quadrante que apresentou variáveis (quadrante I), com a finalidade de analisar de forma mais adequada cada uma das variáveis. Os dados estão apresentados no gráfico 11:

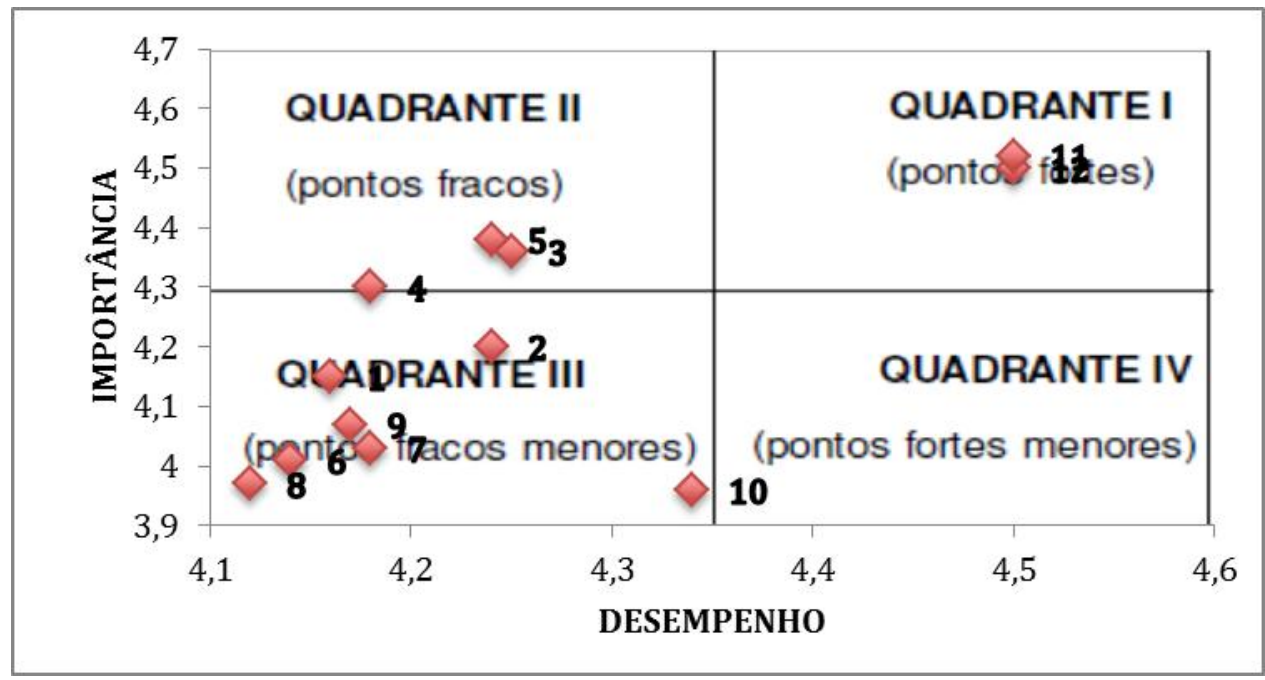

Gráfico 11: Matriz importância $X$ desempenho por quadrantes (com eixos ajustados)

A proposta de Matzler et al. (2004, apud Tontini et al. 2004), a matriz importância $\mathrm{X}$ desempenho possui quatro quadrantes. Após ajustar os eixos do gráfico para focar apenas no quadrante I (tendo como base o gráfico 10 para elaboração do gráfico 11), observam-se variáveis em três quadrantes, ao invés de apenas um quadrante.

O Quadrante I corresponde aos pontos fortes da empresa. Os itens 11 e 12 (Entrega domiciliar e o Estacionamento) são os itens que se encontram dispostos nesse quadrante. Significa que são os itens melhores avaliados pelos consumidores, pois a loja fornece a entrega domiciliar com todos os produtos adquiridos em um curto prazo de entrega. Além disso, possui um amplo estacionamento para clientes, com e sem cobertura.

No Quadrante II estão os itens 3, 4 e 5 (Diversidade de produtos, Exposição dos produtos e Marcas de produtos). Neste quadrante encontram-se os pontos fracos da empresa. São pontos que carecem melhorias, como aumentar a diversidade e marcas oferecidas e modificar a exposição dos produtos para facilitar a localização dos mesmos pelos consumidores.

Os pontos 1, 2, 6, 7, 8, 9 e 10 correspondem a Localização da loja, Ambiente, Preços, Condições de pagamento, Divulgação dos produtos, Atendimento no balcão e Atendimento via telefone. Esses itens estão situados no Quadrante III, representando os pontos que merecem aten- 
ção por parte da empresa, ou seja, são variáveis que em caso de inexistência de investimentos ou melhorias acarretarão prejuízos à empresa, possibilitando a insatisfação dos clientes. Esses itens não representam uma ameaça com a mesma intensidade dos itens do Quadrante II, mas apenas alguns ajustes serão suficientes para impossibilitar futuros prejuízos. Melhorias como alterações de preço, treinamento dos funcionários para assegurar um atendimento de qualidade no balcão e telefone, aumentar a divulgação dos produtos oferecidos e acrescentar variações nas condições de pagamento, são exemplos de ajustes em pequena proporção, porém, com resultado possivelmente satisfatório.

De forma sintética e de fácil visualização, os dados da matriz de importância $\mathrm{X}$ desempenho, apresentada no formato de quadrantes (com aproximação dos eixos) são apresentados na figura 4 :

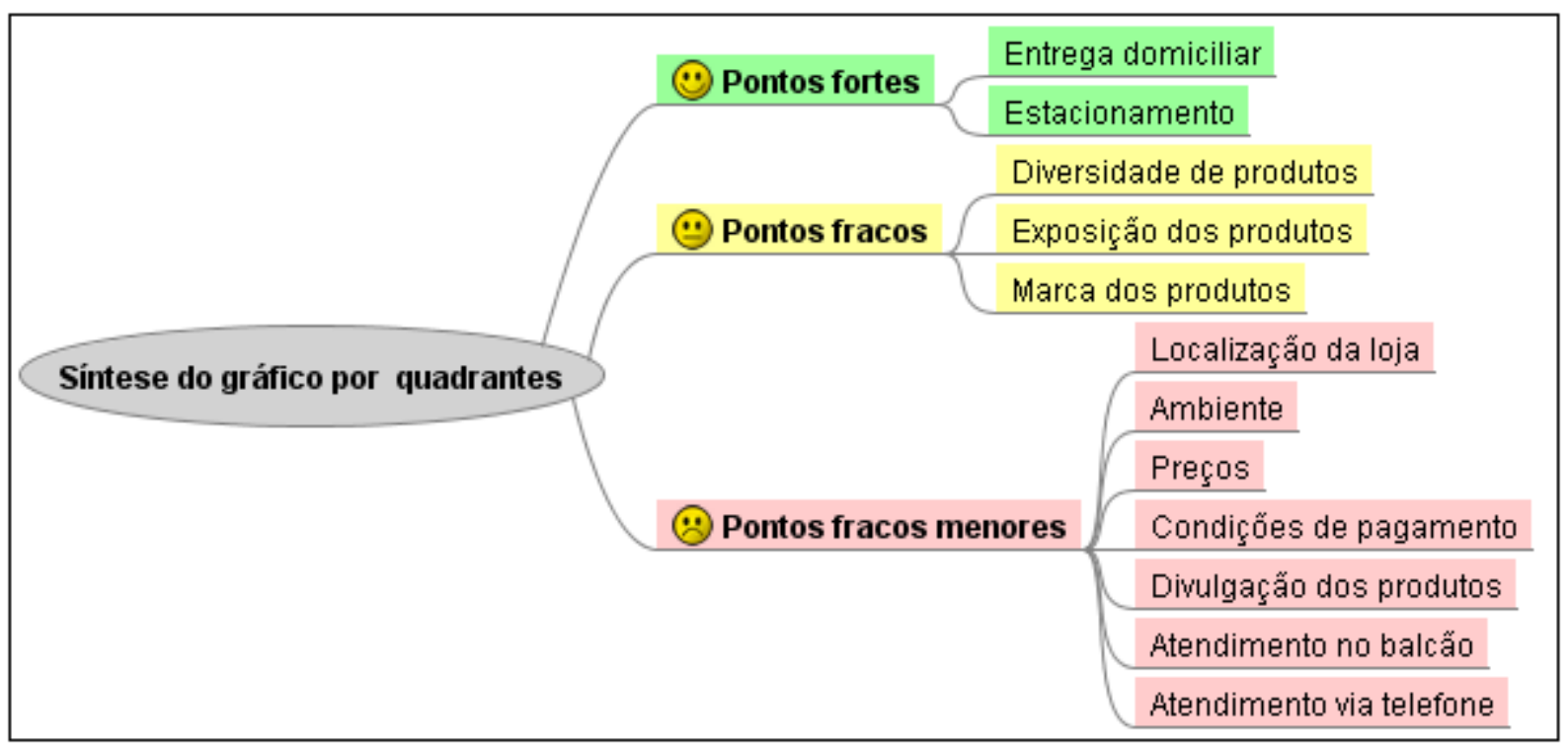

Figura 4: Síntese do gráfico por quadrantes (com ajuste do eixo)

Nesse formato de visualização, é possível observar duas variáveis enquadradas como pontos fortes, três variáveis como pontos fracos e sete variáveis como pontos fracos menores.

Partindo do pressuposto apontado por Tontini e Sant'Ana (2007) que a satisfação dos consumidores está relacionada com o atendimento de necessidades através de um conjunto de características ou atributos do produto, e que para isso torna-se importante descobrir como o desempenho dos diferentes atributos está relacionado à satisfação dos clientes, pode-se afirmar que o modelo de pesquisa desenvolvida é fator importante e contribui significativamente para que a empresa possa conhecer seus clientes.
Das 12 variáveis ou atributos elencados, denota-se através do enquadramento dos itens na matriz proposta por Slack (2003), apresentada no gráfico 9 e sintetizada na figura 3 , que três variáveis foram enquadradas como satisfatórias (zona apropriada), cinco variáveis ficaram na zona de melhoramentos e quatro variáveis na zona de ação urgente.

Considerando a proposta de Slack (2003), em que (i) na zona "apropriada" as características de desempenho devem ser consideradas satisfatórias a curto e médio prazo; (ii) qualquer variável de desempenho abaixo do limite inferior da zona apropriada, estará sujeito a melhoramentos e estará na zona de "melhoria"; (iii) não significando exatamente um item que está prejudicando a empresa ao extremo; na 
zona de "ação urgente" encontram-se as variáveis de desempenho mais críticos, pode-se inferir: as variáveis que estão causando insatisfação para os clientes são apenas quatro em um total de 12 variáveis, sendo: Localização da loja, Diversidade dos produtos, Exposição dos produtos e Marca dos produtos. Seguindo essa analogia, pode-se inferir que os clientes da loja encontram-se satisfeitos com $66,67 \%$ dos itens investigados.

Existem formas de reverter o desempenho do estabelecimento quanto aos quatro itens que os clientes apresentaram insatisfação, pois Mowen e Minor (2003) apontam que o comportamento do consumidor apoia-se sobre as experiências diárias do consumidor. Assim, caso a loja apresente melhorias nos itens de insatisfação, os clientes poderão testar novas experiências sobre aqueles mesmos itens, fazendo com que a sua satisfação seja alterada através das novas experiências.

\section{Considerações finais}

Considerando o marketing como um sistema que designa trocas entre a empresa e o cliente trazendo benefícios a ambos e com o consumidor em uma das extremidades do processo de troca, pode-se aludir que o processo de troca é algo fundamental para o comportamento do consumidor e a satisfação desse consumidor.

Com a aplicação de questionários a 200 clientes da loja de materiais de construção de Itararé-SP, o resultado aponta que a maioria dos consumidores é residente em Itararé $(77 \%)$. A maioria dos clientes é do sexo masculino, e com faixa etária entre 19 e 36 anos, podendo ser construtores, engenheiros civis, arquitetos, pedreiros, auxiliares, mestres de obras, chefes de família, financiadores entre outros. Os clientes casados representam $60 \%$, podendo ser recém-casados construindo/reformando o local onde será o alicerce de sua família ou os próprios pais de família que trabalham no ramo construtor. A renda mensal de $46 \%$ dos consumidores que está entre $\mathrm{R} \$ 700,00$ e $\mathrm{R} \$ 1.400,00$. Quanto à frequência em que os consumidores adquirem produtos na loja, denota-se que $26 \%$ frequentam o estabelecimento várias vezes ao mês.

$\mathrm{Na}$ avaliação da concentração e dispersão das respostas tanto dos itens relativos à importância quanto aos da satisfação (cálculo da estatística descritiva), constatou-se que os itens Entrega domiciliar e Estacionamento atingiram um nível acima da média de importância atribuída para a variável pelos clientes, não necessitando de melhorias. E os itens de Atendimento via telefone e Divulgação dos produtos apresentaram as menores pontuações.

No entanto, as variáveis que apresentam maior satisfação ou desempenho em relação a importância atribuída pelos clientes foram Diversidade de produtos, Exposição dos produtos e Marca dos produtos. Já as variáveis em que predomina a importância em relação à satisfação do cliente com o desempenho da loja foram: Preços, Condições de pagamento, Divulgação dos produtos, Atendimento no balcão, Atendimento via telefone.

Quanto ao cálculo de correlação, denota-se que as variáveis não apresentam correlação significativa entre si, considerando que um resultado forte seria próximo ou acima de 0,7 . O desvio padrão mostra que as variáveis não apresentaram respostas uniformes, obtendo variação média entre 0,6 e 0,9 .

A variável Confiabilidade da empresa foi investigada somente a âmbito de desempenho, sendo que a empresa foi considerada por seus clientes como uma empresa confiável, atingindo 4,58 pontos dos cinco possíveis.

No gráfico de dispersão por quadrantes, com os dados originais (sem ajuste dos eixos), constatou-se que a empresa atingiu um nível satisfatório para todas as variáveis. No entanto, no gráfico com aproximação dos eixos constatou-se que os itens Entrega Domiciliar e o Estaciona- 
mento estão como pontos fortes da empresa. Os itens Diversidade de Produtos, Exposição dos Produtos e Marcas de Produtos como pontos fracos da empresa. E como pontos fracos menores tem-se as variáveis Localização da loja, Ambiente, Preços, Condições de pagamento, Divulgação dos produtos, Atendimento no balcão e Atendimento via telefone.

O fato observado no gráfico por quadrantes se repete no gráfico de dispersão por zonas (proposto por Slack, 2003), em que na matriz importância $X$ desempenho em que com os dados originais (sem aproximação do eixo) todas as variáveis foram consideradas satisfatórias a médio e longo prazo. Assim houve uma necessidade de ajustar os eixos para uma melhor percepção da necessidade de melhorias para cada variável. Com os eixos aproximados, denota-se que os itens Atendimento via Telefone, Entrega Domiciliar e o Estacionamento, respectivamente foram os itens melhores avaliados, considerados satisfatórios para a empresa a médio e longo prazo. Os itens que tiveram resultados abaixo que o esperado são: Localização da Loja, Diversidade de Produtos, Exposição dos Produtos e Marcas dos Produtos. Esses itens necessitam de melhorias em caráter mais urgente ou prioritário.

Se a empresa tomar como base a análise dos quadrantes ou do gráfico de dispersão por zonas sem o ajuste dos eixos, pode-se inferir que todas as variáveis averiguadas na pesquisa de satisfação apresentaram resultados satisfatórios, sendo que a satisfação do cliente foi em $100 \%$ dos itens. Contudo, com a aproximação dos eixos em ambos os gráficos, percebeu-se que os consumidores estão menos satisfeitos principalmente com os itens Localização da loja, Diversidade de produtos, Exposição dos produtos e Marcas dos produtos, sendo que estes podem apresentar algumas melhorias, no intuito de assegurar a confiabilidade, lealdade e satisfação dos consumidores.

A presente pesquisa teve como ob- jetivo mensurar o nível de satisfação dos clientes de uma loja de materiais de construção de Itararé-SP, de acordo com a matriz de importância $\mathrm{x}$ desempenho proposta por Slack. Considerando a proposta de Slack (2003), em que (i) na zona "apropriada" as características de desempenho devem ser consideradas satisfatórias a curto e médio prazo; (ii) qualquer variável de desempenho abaixo do limite inferior da zona apropriada, estará sujeito a melhoramentos e estará na zona de "melhoria"; (iii) não significando exatamente um item que está prejudicando a empresa ao extremo; na zona de "ação urgente" encontram-se as variáveis de desempenho mais críticos, pode-se inferir: as variáveis que estão causando insatisfação para os clientes são apenas quatro (Localização da loja, Diversidade dos produtos, Exposição dos produtos e Marca dos produtos) em um total de 12 variáveis. Seguindo essa analogia, pode-se inferir que os clientes da loja encontram-se satisfeitos com $66,67 \%$ dos itens investigados.

\section{Referências}

BRITO, R. P.; BRITO, E. M. O.; TROVÃO, R. A evolução da teoria de Marketing : Uma discussão epistemológica. Revista de Administração da UNIMEP, v. 4, n. 3, Set. /Dez., 2006.

DOUGHERTY, D. Organization for innovation. In: CLEGG, S.; HARDY, C.; NORD, W. (Orgs.). Handbook of organizational studies. London: Sage, 1996.

GILBERT, A.; CHURCHILL, Jr.; PETER, J. P. Marketing: Criando Valor Para os Clientes. 2. ed. São Paulo: Saraiva, 2000.

KOTLER, P. Administração de Marketing. 10. ed. Prentice-Hall, 2000.

LAMB, C.; HAIR, J.; MCDANIEL, C. Princípios de Marketing. Trad. Luciana Penteado Miquelino. 2. ed. Thomson, 2004. 
LARÁN, J. A.; ROSSI, C. A. V. Surpresa e a formação da satisfação do consumidor. RAE-eletrônica, v. 5, n. 1, jan./jun. 2006.

LEVITT, T. The marketing imagination. New York: The Free Press, 1983.

MATZLER,TONTINI. Análise de oportunidades de melhoria em laboratórios fotográficos através da integração da matriz de Importância x Desempenho com o modelo Kano de qualidade. Blumenau, Revista de Negócios, v.9, n.3, p.179-190, 2004.

MOWEN, J. C.; MINOR, M. S. Comportamento do Consumidor. Trad. Vera Jordan. São Paulo. Person, 2003.

OLIVER, R. L.; RUST, R. T.; VARKI, S. Customer delight: foundations, findings, and managerial insight. Journal of Retailing, v. 73, n. 3, p. 311-336, 1997.

PEREIRA, G. M.; BORCHARDT, M.; GEIGER, A. Uma nova abordagem para o marketing industrial das PMEs: resultados de uma pesquisa-ação. Revista Produção, v. 18, n. 2, p. 331-341, maio/ago. 2008.

ROJO, F. J. G. Pesquisa: o comportamento do consumidor nos supermercados. Revista de Administração de Empresas, São Paulo, v. 38, n. 3, p. 16-24, 1998.

SLACK, N. Vantagem Competitiva em Manufatura: Atingindo Competitividade nas Operações Industriais. Trad. Sônia Maria Corrêa. ed. Atlas, 2003.

TONTINI, G.; SANT'ANA, A. J. Identificação de atributos críticos de satisfação em um serviço através da análise competitiva do gap de melhoria. Revista Gestão e Produção, São Carlos, v. 14, n. 1, p. 4354, jan/abr. 2007.

VANHAMME, J. The influence of the emotion of surprise on consumer's satisfaction: a pilot experiment. In: 31st Conference of European Marketing Academy - EMAC, 2002, Braga, Portugal. Proceedings. European Marketing Academy, 2002, p. 0-6.
VANHAMME, J.; LINDGREEN, A. Gotcha! Findings from an exploratory investigation on the dangers of using deceptive practices in the mail-order business. Psychology and Marketing, v. 18, n. 7, p. 785-810, jul. 2001.

VELUDO-DE-OLIVEIRA, T.; IKEDA; A. A. O conceito de valor para o cliente: definições e implicações gerenciais em marketing. Revista Gestão.Org, v. 3, n. 1, jan./abr. 2005.

WESTBROOK, R. A.; OLIVER, R. L. The dimensionality of consumption emotion patterns and consumer satisfaction. Journal of Consumer Research, vol. 18, p. 84-91, jun. 1991. 